\title{
Fragmentos do contemporâneo:
}

\section{as narrativas de Bernardo Carvalho e Francisco José Viegas}

\begin{abstract}
Adenize Franco ${ }^{1}$
RESUMO: Este artigo tem por objetivo apresentar algumas considerações a respeito da literatura contemporânea. A partir da análise dos romances $O$ sol se põe em São Paulo e Mongólia, de Bernardo Carvalho e de A luz do índico, de Francisco José Viegas, procuro verificar possiveis relações entre as noções de identidade, espaço/tempo e memória que constituem elementos representativos da pós-modernidade.

ABSTRACT: This paper aims to present some considerations on the contemporary literature. Starting from the analysis of the novels $O$ sol se põe em São Paulo, and Mongólia, by Bernardo Carvalho, and A luz do indico, by Francisco José Viegas, I shall verify possible relations among the conceptions of identity, space/time and memory, which are representative elements of the post-modernity.
\end{abstract}

PALAVRAS-CHAVE: Romance contemporâneo; Bernardo Carvalho; Identidade; Espaço narrativo; Francisco José Viegas

KEYWORDS: Contemporary novel; Bernardo Carvalho; Identity; Narrative space; Francisco José Viegas

\section{Fragmento I}

No olho da amêndoa, no damasco, exposto numa lágrima de figo, sabes: eu não sou daqui, nunca cheguei, nunca sai daqui.

(Naschmarkt, Age de Carvalho)

1 Doutoranda em Estudos Comparados de Literaturas de Língua Portuguesa FFLCH/USP. Título provisório do projeto: "As ruinas da contemporaneidade: literatura e resistência em tempos de globalização”. Contato: adenizeafranco@gmail.com 
Toda cidade é um monumento, uma esfinge esquartejada sua alma coletiva nunca vai ser decifrada

(Megalópole cidade, Fernanda Abreu)

No artigo "A literatura brasileira na era da multiplicidade", Beatriz Resende aponta o caráter de multiplicação da literatura contemporânea. Desconsiderando fatores até então vistos como imperativos para o fato de a literatura ser questionada, como por exemplo, a vendagem e problemas de publicação, a autora revela que a afirmação da existência de poucos leitores ou a baixa vendagem de livros demonstra a constatação contrária, já que "se publica muito, que novos escritores e editoras surgem todos os dias, e que comenta-se e consome-se literatura” (RESENDE, 2008, p. 16).

Na sequência, Beatriz Resende elenca uma série de exemplos que justificam sua assertiva: a forma sedutora com que as livrarias tentam atrair seus clientes, os prêmios literários instituídos e o grande valor disponibilizado aos autores premiados, as festas literárias que unem o cult e o pop, com a presença performática de 'icones' da literatura contemporânea.

Tais elementos apontados pela autora nos fazem perceber que, diferentemente do que outros críticos apontavam em passado recente, a literatura contemporânea não está em extinção. Talvez nunca se tenha produzido, publicado, propagado, consumido (até) tantos livros como no momento em que nos encontramos. É interessante perceber, inclusive - evidentemente um panorama que é marcado pelo fácil acesso à internet e aos meios midiáticos - a rapidez com que publicações no exterior são traduzidas aqui e, quando não em lançamento mundial, em breve já estão disponiveis nas gôndolas dos supermercados. 
Essa rapidez poderia ser sinônimo de má qualidade em obras que chegam às vistas dos leitores. Entretanto, como afirma Beatriz Resende no mesmo capítulo, "a prosa que se apresenta vive um momento de grande qualidade" (RESENDE, 2008, p. 17). Nesse sentido, o apreço pela experimentação inovadora, a escrita cuidadosa, a erudição inesperada, a imaginação, a originalidade na escritura e um repertório de referências da tradição literária são algumas das características encontradas nessas obras e mencionadas pela autora.

As qualidades evidenciadas acima aliadas às questões contextuais e representativas do momento contemporâneo são características que podem ser verificadas nas obras do século XXI. Um dos elementos que pode ser observado e que nos leva a pensar a produção literária deste tempo globalizado trata-se das formas de resistência que regem tal produção.

Distante da noção de resistência enquanto processo políticopartidário, algumas obras da atual literatura constroem-se como discursos que promovem a verificação de uma reação a posicionamentos condicionantes que regem a pós-modernidade. Evidentemente observamos obras marcadas pelas categorias que configuram o momento contemporâneo, tais como espaço/tempo, memória, história, fronteiras, deslocamentos, diásporas entre outras. Entretanto, antes de adotar um discurso fragmentado, ou até mesmo, usando-o, mas em seu beneficio e como forma de dar identidade ao que se está produzindo, tais obras literárias expandem as categorias acima citadas ao recorrerem a um processo discursivo que se mostra como resistência às crises pertencentes ao momento.

Vale pensar na definição dicionarizada para o termo resistência. Entre as várias possibilidades de entender o termo, o dicionário Aurélio traz uma que requer especial atenção: 3. força que defende um organismo do desgaste de doença, cansaço etc. Tal definição para o vocábulo complementa a ideia de que na era da globalização ainda há motivos para a literatura resistir ao desgaste. Há motivos para crermos que a literatura, à parte as dificuldades já vistas, encontra em 
determinados autores e em formas diferenciadas modos de promover discursos que demonstram essa tentativa de resistir, de não cair na 'vala comum' do esquecimento ou do passageiro.

\section{Fragmento II}

Em uma das passagens do romance $O$ sol se põe em São Paulo (2007), de Bernardo Carvalho, o narrador ao ser contratado pela dona do restaurante do bairro da Liberdade comenta

Queria provar a tese de que a literatura é (ou foi) uma forma dissimulada de profetizar no mundo da razão, um mundo esvaziado de mitos; que ela é (ou foi) um substituto moderno das profecias, agora que elas se tornaram ridiculas, antes que a própria literatura também se tornasse ridícula. (CARVALHO, 2007, p. 23)

Esse fragmento pode ser o ponto de partida para algumas considerações a respeito da literatura na era da contemporaneidade. Num momento em que muitos dos mitos já se dissolveram e/ou foram re-considerados, pensar na existência da literatura enquanto profecia ou substituto para algumas profecias, se não for mesmo impossivel, é quase isso.

O narrador de $O$ sol se põe em São Paulo deixa entrever a questão do esvaziamento que marca as considerações que permeiam a literatura atualmente. Postulando, em sua tese, que a literatura seja dissimulação e esvaziamento de mitos, não deixa de corroborar a tese de muitos críticos, filósofos e historiadores de que a literatura pode ter chegado ao seu fim. Por outro lado, reverbera a ideia que cerceia as concepções pós-modernistas de ruptura das verdades estabelecidas.

Num primeiro momento, podemos observar que a afirmação do narrador coaduna-se com a concepção do crítico Terry Eagleton que, ao definir o conceito de pós-modernidade, afirma tratar-se esta de

uma linha de pensamento que questiona as noções clássicas de verdade, razão, identidade e objetividade, a idéia de progresso ou 
emancipação universal, os sistemas únicos, as grandes narrativas ou os fundamentos definitivos de explicação. (...) vê o mundo como contingente, gratuito, instável, imprevisivel, um conjunto de culturas ou interpretações desunificadas gerando um certo grau de ceticismo em relação à objetividade da verdade, da história e das normas, em relação às idiossincrasias e a coerência de identidades. (EAGLETON, 1998, p. 7)

Ou seja, as noções fulcrais que regem esse período como as citadas pelo teórico estão em constante questionamento. Trata-se de um momento marcado pela instabilidade, pela fluidez, pela imprevisibilidade e que conduz à descrença da objetividade da verdade, gerando, portanto, o esfacelamento de conceitos como identidade, memória, história e tempo/espaço. A concepção de Eagleton, aliada ao posicionamento do narrador de $O$ sol se põe..., coloca em evidência o questionamento que rege as noções do contemporâneo.

Além disso, ao questionar esses conceitos, teórico e romancista acabam por trazer à baila novas categorias que, também, tornam-se tópicos de discussão. Tais categorias são assinaladas por Andreas Huyssen em seu livro Seduzidos pela memória (2000).

o foco contemporâneo na memória e na temporalidade também contrasta em muitos outros trabalhos inovadores sobre categorias de espaço, mapas, geografias, fronteiras, rotas de comércio, migrações, deslocamentos e diásporas, no contexto dos estudos culturais e pós-coloniais. (...) para entender a cultura pós-moderna o foco devia ser deslocado da problemática do tempo e da memória (...) para uma outra na qual o espaço é uma peça-chave do momento pós-moderno. (p. 9-10)

Considerando a assertiva acima, podemos perceber que não somente memória e tempo são categorias que se encontram em conflito na pós-modernidade, mas ainda temos outras que avançam e se colocam diante da discussão no momento atual. Todas as categorias citadas por Huyssen podem ser observadas em produções literárias contemporâneas, independente, inclusive, de sua localização geográfica, uma vez que as próprias marcas fronteiriças são instáveis. À parte a 
dissolução física das fronteiras, vale ressaltar que a pós-modernidade atinge todos os espaços e abarca os mais variados niveis sociais.

\section{Fragmento III}

Apoiando-nos em outro fragmento do romance $O$ sol se põe em São Paulo, de Bernardo Carvalho, podemos observar uma das categorias mencionadas por Andreas Huyssen. Trata-se da dissolução de tempoespaço. Vejamos,

São Paulo não se enxerga - ou não chamaria periferia de periferia. Não é só eufemismo. Chamam-se excluídos aos oitenta por cento da população. Não é à toa que é uma cidade de publicitários. Em São Paulo, publicidade é literatura, expliquei ao homem com lábio leporino, em inglês, sem deixar claro se fazia uma crítica ou me justificava. É uma cidade que quer estar em outro lugar e em outro tempo. E essa vontade só a faz ser cada vez mais o que é e o que não quer ser. (...) Cada imigrante, achando que transplantava o estilo da sua terra e dos antepassados, acabou contribuindo para a caricatura local. (...) Não é só que esteja tudo fora do lugar. Está tudo fora do tempo também. Na Liberdade, nem mesmo um bêbado, ao sair trôpego de um restaurante, acreditando que é escritor, pode achar que está numa viela tranqüila dos subúrbios de Tóquio e não numa megalópole violenta do Terceiro Mundo. E, no entanto, é disso que as ruas de São Paulo tentam convencer quem passa por elas: que está em outro lugar, num esforço inútil de aliviar a tensão e o incômodo de estar aqui, o malestar de viver no presente e de ser o que é. (CARVALHO, 2007, p. 12-14, grifos meus)

No texto acima, as passagens em negrito demonstram o deslocamento de espaço. O narrador-escritor ultrapassa uma localização imediata e totalizante. Ao mesmo tempo em que está em um restaurante no Bairro Liberdade, em São Paulo, o parágrafo seguinte já desloca o leitor para um ano depois em um apartamento em Tóquio. O deslocamento que se dá, não somente em termos espaciais, mas também temporais, de certa maneira corrobora o pensamento de Huyssen mencionado anteriormente, pois também recupera a guerra do 
Pacífico e a interioridade de um fazenda no interior de São Paulo dos dias atuais. Além disso, o espaço é fundamental, uma vez que no trecho assinalado a descrição do Bairro Liberdade serve de introdução para explicar o título da obra: "O pôr-do-sol em São Paulo é reputado como um dos mais espetaculares, por causa da poluição”. De um espaço localizado, o bairro Liberdade, o narrador lança-se à descrição dos prédios-monumentos 'imaginários' de São Paulo.

Nessa passagem, somos conduzidos à seguinte afirmação “a cidade tem de mais pobre e paradoxalmente mais autêntico: a vontade de passar pelo que não é." Podemos perceber novamente a deslocalização, no sentido em que o bairro Liberdade (espaço característico de descendentes japoneses) jamais será uma viela do subúrbio em Tóquio. Ao passo que tenta representar esse espaço. Além disso, essa tentativa de se passar pelo que não é nos possibilita pensar nas questões discutidas acerca das fronteiras.

Segundo Zygmunt Bauman, em Globalização: as consequências humanas, "As distâncias já não importam, ao passo que a idéia de uma fronteira geográfica é cada vez mais dificil de sustentar no "mundo real"' (1999, p. 19). Desse modo, é possivel verificar no fragmento assinalado justamente o fato de as distâncias não serem relevantes. Como o filósofo afirma em outro momento,

Não há mais "fronteiras naturais" nem lugares óbvios a ocupar. Onde quer que estejamos, em determinado momento, não podemos evitar de saber que poderíamos estar em outra parte, de modo que há cada vez menos razão para ficar em algum lugar específico (e, por isso, muitas vezes, sentimos uma ânsia premente de encontrar - de inventar - uma razão). (BAUMAN, 1999 , p. 85)

Característico de Bernardo Carvalho é esse trânsito constante. Seja do Bairro Liberdade, em São Paulo a Tóquio; seja do Brasil à Mongólia e China; seja da fronteira do Maranhão, imerso numa tribo de índios Krahô a Nova York, ou como em seu último romance, O filho da mãe (2009), de São Petersburgo ao Brasil. 
Além do exemplo visto em $O$ sol se põe em São Paulo vale observar essa passagem extraída de Mongólia:

Almoçaram na relva. $O$ Ocidental aproveitou para afinal expressar a sua insatisfação. Estava impaciente. Lembrou a Purevbaatar que tinha uma missão - encontrar o rapaz desaparecido - e que o desvio para visitar os parentes do guia não estava em seus planos. Mas Purevbaatar, ao perceber a irritação do cliente, não se fez de rogado. Podia estar sendo pago, mas também tinha seus brios e não levava desaforo para casa. "Talvez você não tenha entendido o meu trabalho quando me contratou. Não brinco em serviço. Você me pediu para fazer o mesmo percurso que fiz com ele há seis meses. Acontece que esse percurso depende das pessoas que encontramos no caminho. Num país de nômades, por definição, as pessoas nunca estão no mesmo lugar. Mudam conforme as estações. Os lugares são as pessoas. Você não está procurando um lugar. Está procurando uma pessoa. Pois é atrás dela que eu estou indo". (CARVALHO, 2003, p. 115, grifos meus.)

Novamente, as partes em negrito corroboram a ideia de mobilidade dos lugares, logo a dificuldade de se estabelecer um território geográfico. Em tempos de globalização, as fronteiras geográficas se perdem e na metáfora do texto lugar = pessoa, vemo-nos diante de outra categoria também volátil e transitória.

Esse trânsito também é o responsável pela construção identitária das personagens. Como são representadas em espaços/tempos deslocados, tendem a partilhar dessa categoria à semelhança da assertiva de José Manuel Oliveira Mendes em "O desafio das identidades" (2002), que, apoiado em Boaventura de Sousa Santos, diz, "as identidades são definidas como negociações de sentido, como jogos de polissemia, como identificações em curso" (p. 517). Logo, é possivel verificar nas obras de Bernardo Carvalho a representação dessas identidades fluidas que caracterizam o sujeito pós-moderno.

Foi chamado de Ocidental por nômades que não conseguiam dizer o seu nome quando viajou pelos confins da Mongólia. Fazia tempo que eu não ouvia falar dele, até ler a reportagem no jornal. Voltou da China há cinco anos e largou a carreira diplomática. Sua volta intempestiva coincidiu com a eclosão da crise da pneumonia atípica na Ásia, o que pode ter servido de explicação para alguns, mas não para mim. O jornal diz que ele morreu 
num tiroteio entre a polícia e uma quadrilha de seqüestradores, quando ia pagar o resgate do filho menor no morro do Pavãozinho. Pela idade do garoto, só pode ser o que nasceu em Xangai, logo antes de voltarem para o Brasil, quando ele decidiu mudar de vida sem dar satisfações a ninguém. (CARVALHO, 2003, p. 9)

A descrição acima, referente ao Ocidental, não só recupera elementos anteriormente apresentados, como a dissolução do tempo, mas ainda a construção da identidade do personagem denominado Ocidental. Essa falta de nome próprio e o reconhecimento como estrangeiro permite entrever essa definição de 'identidades em curso' referida por Boaventura de Sousa Santos. Os nômades da Mongólia não sabiam pronunciar o nome do vice-cônsul de Xangai, responsável pela procura do desaparecido, que, por sua vez, era tratado como Buruu nomton. Este, além de desaparecido é desconhecido, uma vez que durante toda a narrativa apenas é referido como o desajustado.

Vale, ainda, recuperar o conceito de 'identidade narrativa', explícito em José Manuel de Oliveira Mendes. Para o autor, a narrativa "descreve, conta e prescreve. (...) refigura o tempo e, partindo da memória construída na continuidade da vida, procura dar-lhe a forma de uma experiência humana" (p. 521). Partindo desse pressuposto, aliado às propostas de Paul Ricouer que sustentam o raciocínio de João Manuel, da existência de uma dialética entre a mesmidade e a ispseidade (dimensão moral), é possível verificar nas obras analisadas a presença da memória como elemento construtor das narrativas que, por sua vez, dentro do processo discursivo constroem as identidades dos personagens. Se a narrativa, ao refigurar o tempo, dá a este a forma de uma experiência humana, logo é plausível que em narrativas ficcionais vejamos representada essa forma de reconfiguração.

A respeito da memória, referida acima por José Manuel de Oliveira Mendes, convém recuperar a citação de Andreas Huyssen, de que

insistir numa separação radical entre memória 'real' e virtual choca-me tanto quanto um quixotismo, quando menos porque 
qualquer coisa recordada - pela memória vivida ou imaginada - é virtual por sua própria natureza. A memória é sempre transitória, notoriamente não confiável e passivel de esquecimento; em suma, ela é humana e social. (2000, p. 37)

Percebemos, diante disso, que não somente espaço, tempo e identidade são categorias transitórias na pós-modernidade, mas também a categoria memória, uma vez que é 'humana e social'. Nesse sentido, vale recuperar a passagem de Mongólia que representa, de certa maneira, o pensamento de Huyssen.

Não dá para saber quando e onde a história começa. Uma coisa leva a outra, e a coerência parece só ter efeito retroativo. Está escrito no diário do rapaz: "Ninguém sabe nada de lugar nenhum. Aprenderam a não se comprometer. O passado, quando não se perdeu, agora são lendas e suposições nebulosas. Eles não têm outro uso para a imaginação. Durante séculos, os lamas se encarregaram de imaginar por eles. Durante setenta anos, o partido se encarregou de lembrar por eles, no lugar deles. Agora lembrar é imaginar. Às vezes prefiro quando dizem que não sabem ou não se lembram de nada". (CARVALHO, 2003, p. 132)

O discurso dentro de outro discurso (o Ocidental escrevendo uma carta dentro da qual consta um fragmento do diário do desajustado/desaparecido) permite verificarmos essa constatação acerca da memória. Se para o desaparecido lembrar é imaginar, temos aí a construção não somente do romance como elaboração ficcional, mas dentro dele (mise en abyme) as construções possíveis para a história dos lugares pelos quais os personagens transitam. A história é imaginada e a memória construída em função dessa história.

\section{Fragmento IV}

Vale a pena frisar ainda que não somente na literatura brasileira contemporânea encontramos esse traço da dissolução das fronteiras. Em uma observação, ainda que panorâmica, conseguimos perceber em obras de literaturas de língua portuguesa a presença dos elementos aqui assinalados. Tanto em obras produzidas por autores de Portugal (José Luis Peixoto, José Saramago e Francisco José Viegas, por 
exemplo) ou de Angola (José Eduardo Agualusa, especialmente) podem ser verificados esfacelamentos de conceitos, alguns destes aqui abordados.

Neste ensaio, a título de conhecimento e de introdução a um trabalho que está em desenvolvimento, apontaremos, de forma tangencial, um exemplo que se não dialoga explicitamente com os romances de Bernardo Carvalho aqui trabalhados, explora - de forma análoga - elementos característicos da contemporaneidade. Trata-se do romance Lourenço Marques, de Francisco José Viegas, publicado em 2002 e que recebeu, no Brasil, o título de A luz do Índico.

O trecho que segue nos possibilita verificar a presença de um elemento significativo nas construções narrativas do período atual. Dentro de um discurso narrativo fragmentário, marcado pelo uso do indireto livre em que se percebe a interrupção por memórias que se atropelam, o narrador tenta construir sua identidade.

E então chegaram mais primos, primos ainda mais sujos e mais pobres, sem nada, alguns ficaram a viver lá em casa, ocuparam os dois quartos que sobravam, vinham de África, "tinham perdido tudo". Como se perde tudo assim de repente? Como se perde a vida em caixotes alinhados em Alcântara, onde foram buscar um deles, um caixote com mobilias desfeitas, um gira-discos antigo, uma colecção de quadros com paisagens da Gorongosa, dois serviços de jantar comprados na África do Sul, um tapete comprado no monhés de Porto Amélia, colheres de pau, roupa de cama e velhas camisas brancas de manga curta que já não se usavam aqui. Mas o que mais havia era a raiva e muitas lágrimas, e ele teria 18 anos, 18?, muita raiva, mas a vida é assim mesmo, 25 anos depois já não há raiva, o tempo destruiu o coração, só isso, o tempo destruiu o próprio tempo, e só há relatos de gente que se encontra, nasci na cidade da Beira, actualmente resido em Ottawa Canadá, kanimambo maningue, ai os sítios da malta, o clube Náutico, Macuti, Maristas, ATCM, praça da Índia, morei perto do Náutico, nas casas do BNU, o meu coração está sempre em Sofala e Manica, sou macua de Nampula, estudei no Vasco da Gama e Maristas de Lourenço Marques, revejo Nampula muitas vezes, revejo Nampula como um clarão no alto do céu, um relâmpago que ilumina a praia das Chocas, a ilha de Moçambique, Nacala, vim de Quelimane em 1974 e actualmente vivo no Porto, nasci em Nampula em 1965 e fui para Portugal em 1974, em 1977 fui para o Brasil, andei sempre a busca de notícias, nasci em Mocuba, "Onde todos os caminhos se cruzam e a Zambézia me abraça" (...) (VIEGAS, 2007, p. 99-100) 
Neste fragmento podemos observar não apenas a dissolução do espaço, mas também que as fronteiras do tempo são diluídas. A frase impressa "O tempo destruiu o próprio tempo" solidifica a própria construção narrativa, ou seja, o passar do tempo dilui as fronteiras entre passado, presente e futuro, "tudo ao mesmo tempo agora" como sugere o título do cd de 1991, da Banda Titãs, em frase que se tornou expressão corrente.

As categorias espaço-tempo são percebidas de forma a corroborar a existência das identidades. Estão imbricadas para promover o questionamento acerca de outra categoria, que é a de deslocamento. Vemos nas insistentes referências aos lugares de onde vim e para onde fui esse trânsito identitário que situa, num mesmo discurso, espaços distintos e distantes, mas que se atravessam. Seja o passado em Nampula e o presente em Portugal e Brasil, ou da ilha de Moçambique passando por Quelimane e Porto, ou de Beira a Ottawa, percebemos que o trânsito corrente é marca das vozes discursivas que se misturam na passagem. Assim temos um macua que está tanto em Nampula quanto em qualquer um dos outros centros e que ouve reverberar, distante, palavras de uma língua que é/era sua: kanimambo maningue.

Essa frase de agradecimento, interposta entre as várias referências espaciais, promove o questionamento: muito obrigado a quê ou a quem? Deslocada no próprio discurso, qual sua intenção? Talvez, a de tentar ser um elo entre o passado e o futuro que, através do elemento linguístico, recupera toda a história do personagem Miguel, uma vez que todos os espaços e depoimentos se intercruzam nesse jorro narrativo e atravessam sua construção identitária.

Enfim, se fizermos uma averiguação das obras lidas identificamos esse traço que as aproxima. Os personagens estão sempre em trânsito e, normalmente em busca de algo. Esse algo talvez possa ser entendido como a busca de si mesmos ou de uma identidade que não se perdeu, mas que vai se construindo durante a narrativa. 
O fragmento do romance Lourenço Marques evidencia, a partir do deslocamento de espaços, sejam estes cidades que deixaram de ter o nome passado (Lourenço Marques é atual Maputo), sejam lugares dentro dessas cidades e que, por sua vez, evocam um passado recuperado pela memória e, portanto, já não se sabe se realmente existiu, a característica que rege os romances analisados.

Tanto as obras literárias de Bernardo Carvalho, aqui assinaladas, quanto o romance de Francisco José Viegas, levam-nos a recuperar a definição de resistência mencionada anteriormente: força que defende um organismo do desgaste de doença, cansaço etc. Algumas obras da literatura atual, em especial as aqui destacadas, emergem não somente como modos de resistir, seja ao espaço mercadológico, seja à velocidade com que obras se apresentam e caem no esquecimento, ou ainda, ao próprio desconhecimento de seu conteúdo.

É possivel perceber uma literatura que é em si própria a representação de uma luta/defesa contra elementos que estão provocando seu desgaste. Não se pode pensar, evidentemente, a literatura como anticorpos de um corpo/mundo doente. Mas sim como uma força que tem tentado desafiar os perigos da pós-modernidade e, assim, se fazer presente enquanto possibilidade de intercambiar experiências'.

A minha vida A tua vida Fragmento à deriva Nessa bomba de ocorrências

Que é a vida na cidade Onde as pessoas são vetores obscenos da urgência Do que a gente nunca sabe muito bem

(Megalópole-cidade, Fernanda Abreu)

\section{Referências bibliográficas}

ABREU, Fernanda. Entidade urbana. São Paulo: Gravadora EMI, 2000. 
BAUMAN, Z. Globalização: as consequências humanas. Trad. Marcus Penchel. Rio de Janeiro: Jorge Zahar, 1999.

CARVALHO, Age de. "Naschmarkt" In: PINTO, Manuel da Costa. Antologia comentada da poesia brasileira do século XXI. São Paulo: Publifolha, 2006, p.126.

CARVAlHO, B. O sol se põe em São Paulo. São Paulo: Companhia das Letras, 2007. Mongólia. São Paulo: Companhia das Letras, 2003.

EAGLETON, T. As ilusões da pós-modernidade. Trad. Elizabeth Barbosa. Rio de Janeiro: Jorge Zahar, 1998.

HUYSSEN, A. Seduzidos pela memória: arquitetura, monumentos e midia. Rio de Janeiro: Aeroplano/MAM/UCAM, 2000.

MENDES, J. M. “O desafio das identidades" In: SANTOS, B. S. (org.) A globalização e as ciências sociais. São Paulo: Cortez, 2002, p. 503-40.

MIRANDA, Carlos E. "O mal estar no romance contemporâneo" In: Revista Cult. 69, ano IV, maio/2003. São Paulo: Editora 17, 2003, p. 18-21.

RESENDE, Beatriz. Contemporâneos: expressões da literatura brasileira no século XXI. Rio de Janeiro: Casa da palavra/Biblioteca Nacional, 2008.

VIEGAS, Francisco José. A luz do Índico. Rio de Janeiro: Língua Geral, 2007. 